\title{
EDITORIAL
}

\section{Quality control: a necessary, but sometimes overlooked, tool for improving respiratory medicine}

\author{
R. Farré ${ }^{\star \#}$ and D. Navajas*,\#,
}

$\mathbf{T}$ he importance of quality control in both general and respiratory medicine has increased in parallel with the complexity of healthcare provision. Only a few decades ago, the respiratory physician and/or scientist had a very limited number of diagnostic and therapeutic tools available and, moreover, medical practice was based almost exclusively on the personal interaction between doctor and patient. Consequently, at that time the quality of the respiratory healthcare depended entirely on the professional competence of the doctor. Although nowadays the relationship between physician and patient undoubtedly still lies at the heart of respiratory medical practice, the quality of the medical service received by the patient also depends on many other participants in a complex healthcare network: various medical specialists, lung function technicians, nurses, respiratory therapists, social workers and administrative staff. Accordingly, several quality control programmes are applied in order to avoid, or at least to reduce, errors in diagnosis, improper performance of procedures, errors in medication, and failure to supervise or monitor care or recognise complications associated with treatment [1].

An adequate quality control scheme seeks to cover the various levels involved in a healthcare system, all of them with a potential influence on clinical and socioeconomic outcomes. The attending physician is at the centre of the system and, therefore, is perhaps the main element that needs to be assessed in quality control procedures [2]. The results achieved by a given respiratory physician and/or scientist depend, however, on the performance of several professional collaborators in the hospital, each with their own quality assessment programme: specimen laboratories [3, 4], screening [5] and surgical $[6,7]$ procedures, and intensive care units $[8,9]$. It is interesting to note that, in the light of the increasing complexity of the procedures in use, some quality assessment techniques previously developed for industrial environments have recently been applied to the monitoring of healthcare processes $[10,11]$. Home mechanical ventilation and long-term

*Unitat de Biofísica i Bioenginyeria, Facultat de Medicina, Universitat de Barcelona, IDIBAPS, "Institut de Bioenginyeria de Catalunya, Barcelona, and ${ }^{\#}$ CIBER Enfermedades Respiratorias, Spain.

SUPPORT STATEMENT: R. Farré and D. Navajas are supported by Ministerio de Ciencia e Innovación (SAF2008-02991) and Ministerio de Sanidad y Consumo (FIS2008-PI081908), respectively.

STATEMENT OF INTEREST: None declared

CORRESPONDENCE: R. Farré, Unitat de Biofísica i Bioenginyeria, Facultat Medicina, Casanova 143, 08036 Barcelona, Spain. Fax: 34 934035278. E-mail: rfarre@ub.edu oxygen therapy, although not always provided by the prescribing hospital [12], are important respiratory healthcare services with specific quality control protocols $[13,14]$. It is noticeable that quality control plays an important role, not only in optimising the healthcare provided to the population via services directly applied to each individual patient, but also in more general and indirect procedures. This is the case, for example, in clinical trials aimed at implementing guidelines or at investigating pharmaceutical drugs $[15,16]$, in the legal and administrative settings for publishing alerts on adverse incidents [12], in publishing research [17] or in issues concerning the use of diagnostic and therapeutic devices $[18,19]$.

Assessing the safety and effectiveness of medical devices is particularly relevant in respiratory medicine [20]. One reason for this is the fast advance of technology [21], resulting in the marketing of considerably complex and intelligent devices to apply ventilatory support to patients with acute/chronic respiratory failure or sleep apnoea [22-24]. Another reason is the central role that devices measuring lung function play in defining and classifying the degree of severity of respiratory diseases. In this regard, both the American Thoracic Society and the European Respiratory Society have published joint standardisation rules on quality control of the calibration, processing and interpretation of most lung function devices and tests [2527]. Moreover, given the central role that spirometry plays in the routine assessment of lung function, quality control studies have been carried out to investigate whether spirometry can be reliably performed in particularly difficult contexts, such as paediatrics [28], primary care centres [29], multicentre trials [30] and procedures using telemedicine tools [31].

In the present issue of the European Respiratory Journal, JENSEN et al. [32] report the application of a quality control programme to the measurement of the single-breath diffusing capacity of the lung for carbon monoxide $(D \mathrm{~L}, \mathrm{CO})$ in a multicentre clinical trial involving 125 lung function laboratories from most parts of the world. Even though specific standardisation rules for $D \mathrm{~L}, \mathrm{CO}$ measurements have been issued [27], the routine application of this technique exhibits remarkable variability, which makes it difficult to compare data obtained from different laboratories in clinical trials. One source of variability that can be reduced, but not eliminated, comes from the practical implementation of the measurements in each laboratory and patients' biological variability [33]. However, DL,CO tests, like any other lung function measurement, are also affected by instrumental variability, which can and must be considerably reduced, and even eliminated, by quality assurance processes based on 
patient simulators. In fact, JENSEN et al. [32] show that at the beginning of the trial as many as $25 \%$ of lung function laboratories did not pass the quality control tests on $D \mathrm{~L}, \mathrm{CO}$ equipment (a figure that was reduced to $1 \%$ after the initial control). Interestingly, the performance of the $D \mathrm{~L}, \mathrm{CO}$ equipment after the initial certification remained constant throughout the quality assurance process undertaken during the clinical trial [32].

The kind of results obtained by JENSEN et al. [32] may seem trivial and predictable from a medical or scientific viewpoint that focuses exclusively on the clinical trial in which the equipment is used, and assuming that there are no methodological anomalies. However, as the proverb says, "the devil is in the details". In any case, it seems clear that attention to quality control in all the specific tasks involved in respiratory healthcare will ultimately result in improvements in patient care.

\section{REFERENCES}

1 Luce JM. Medical malpractice and the chest physician. Chest 2008; 134: 1044-1050.

2 Kaldjian LC, Forman-Hoffman VL, Jones EW, Wu BJ, Levi BH, Rosenthal GE. Do faculty and resident physicians discuss their medical errors? J Med Ethics 2008; 34: 717-722.

3 Al Balooshi N, Jamsheer A, Botta GA. Impact of introducing quality control/quality assurance (QC/QA) guidelines in respiratory specimen processing. Clin Microbiol Infect 2003; 9: 810-815.

4 Wagar EA, Stankovic AK, Raab S, Nakhleh RE, Walsh MK. Specimen labeling errors: a Q-probes analysis of 147 clinical laboratories. Arch Pathol Lab Med 2008; 132: 1617-1622.

5 Sagawa M, Endo C, Sato M, et al. Four years experience of the survey on quality control of lung cancer screening system in Japan. Lung Cancer 2009; 63: 291-294.

6 Ginsberg RJ. Lung cancer surgery: acceptable morbidity and mortality, expected results and quality control. Surg Oncol 2002; 11: 263-266.

7 Nakhleh RE. Patient safety and error reduction in surgical pathology. Arch Pathol Lab Med 2008; 132: 181-185.

8 Curtis JR, Cook DJ, Wall RJ, et al. Intensive care unit quality improvement: a "how-to" guide for the interdisciplinary team. Crit Care Med 2006; 34: 211-218.

9 Najjar-Pellet J, Jonquet O, Jambou P, Fabry J. Quality assessment in intensive care units: proposal for a scoring system in terms of structure and process. Intensive Care Med 2008; 34: 278-285.

10 Axelrod DA, Guidinger MK, Metzger RA, Wiesner RH, Webb RL, Merion RM. Transplant center quality assessment using a continuously updatable, risk-adjusted technique (CUSUM). Am J Transplant 2006; 6: 313-323.

11 Furman C, Caplan R. Applying the Toyota Production System: using a patient safety alert system to reduce error. Jt Comm J Qual Patient Saf 2007; 33: 376-386.

12 Farré R, Lloyd-Owen SJ, Ambrosino N, et al. Quality control of equipment in home mechanical ventilation: a European survey. Eur Respir J 2005; 26: 86-94.

13 Farré R, Navajas D, Prats E, et al. Performance of mechanical ventilators at the patient's home: a multicentre quality control study. Thorax 2006; 61: 400-404.
14 Gustafson T, Lofdahl K, Strom K. A model of quality assessment in patients on long-term oxygen therapy. Respir Med 2008 [Epub ahead of print PMID: 18980837].

15 McGregor M, Cambron JA, Jedlicka J, Gudavalli MR. Clinical trial variability: quality control in a randomized clinical trial. Contemp Clin Trials 2009; 30: 20-23.

16 Rising K, Bacchetti P, Bero L. Reporting bias in drug trials submitted to the Food and Drug Administration: review of publication and presentation. PLoS Med 2008; 5: e217.

17 Schroter S, Tite L, Hutchings A, Black N. Differences in review quality and recommendations for publication between peer reviewers suggested by authors or by editors. JAMA 2006; 295: 314-317.

18 European Community Council. Council Directive 93/42/ EEC of 14 June 1993 concerning medical devices. Official Journal L 1993; 169: 1-43.

19 Maisel WH. Medical device regulation: an introduction for the practicing physician. Ann Intern Med 2004; 140: 296-302.

20 Feldman MD, Petersen AJ, Karliner LS, Tice JA. Who is responsible for evaluating the safety and effectiveness of medical devices? The role of independent technology assessment. J Gen Intern Med 2008; 23: Suppl. 1, 57-63.

21 Redline S, Sanders M. A quagmire for clinicians: when technological advances exceed clinical knowledge. Thorax 1999; 54: 474-475.

22 Fauroux B, Leroux K, Desmarais G, et al. Performance of ventilators for noninvasive positive-pressure ventilation in children. Eur Respir J 2008; 31: 1300-1307.

23 Farré R, Montserrat JM, Rigau J, Trepat X, Pinto P, Navajas D. Response of automatic continuous positive airway pressure devices to different sleep breathing patterns: a bench study. Am J Respir Crit Care Med 2002; 166: 469-473.

24 Rigau J, Montserrat JM, Wohrle H, et al. Bench model to simulate upper airway obstruction for analyzing automatic continuous positive airway pressure devices. Chest 2006; 130: 350-361.

25 Miller MR, Hankinson J, Brusasco V, et al. Standardisation of spirometry. Eur Respir J 2005; 26: 319-338.

26 Wanger J, Clausen JL, Coates A, et al. Standardisation of the measurement of lung volumes. Eur Respir J 2005; 26: 511-522.

27 MacIntyre N, Crapo RO, Viegi G, et al. Standardisation of the single-breath determination of carbon monoxide uptake in the lung. Eur Respir J 2005; 26: 720-735.

28 Kirkby J, Welsh L, Lum S, et al. The EPICure study: Comparison of pediatric spirometry in community and laboratory settings. Pediatr Pulmonol 2008; 43: 1233-1241.

29 Derom E, van Weel C, Liistro G, et al. Primary care spirometry. Eur Respir J 2008; 31: 197-203.

30 Pellegrino R, Decramer M, van Schayck CP, et al. Quality control of spirometry: a lesson from the BRONCUS trial. Eur Respir J 2005; 26: 1104-1109.

31 Finkelstein J, Cabrera M, Hripcsak G. Internet-based home asthma telemonitoring. Can patients handle the technology? Chest 2000; 117: 148-155.

32 Jensen R, Leyk M, Crapo R, Muchmore D, Berclaz PY. Quality control of $D \mathrm{~L}, \mathrm{CO}$ instruments in global clinical trials. Eur Respir J 2009; 33: 828-834.

33 Wise RA, Teeter JG, Jensen RL, et al. Standardization of the single-breath diffusing capacity in a multicenter clinical trial. Chest 2007; 132: 1191-1197. 